\title{
An epidemiological study of lung cancer: history and histological types in a general population in northern Finland
}

\author{
R. Mäkitaro*, P. Pääkkö**, E. Huhti*, R. Bloigu+, V.L. Kinnula*
}

\begin{abstract}
An epidemiological study of lung cancer: history and histological types in a general population in northern Finland. R. Mäkitaro, P. Pääkkö, E. Huhti, R. Bloigu, V.L. Kinnula. (C) ERS Journals Ltd 1999.

ABSTRACT: A prospective epidemiological study was conducted to assess the incidence, diagnosis, histology and surgical treatment of lung cancer in northern Finland. The results were compared with those obtained in a similar survey 20 yrs earlier.

Most of the patients with a suspected lung tumour were interviewed $(72 \%)$ and the information was combined with that obtained from the national cancer registry. All pathological specimens were re-evaluated by a pathologist.

A total of 602 new lung cancer cases ( $85 \%$ male, $15 \%$ female) were diagnosed during the years 1990-1992, the annual incidence per 100,000 being 63 for males and 9.5 for females. The number not reported to the Finnish Cancer Registry was low $(<1 \%)$. Lung cancer was confirmed histologically in 381 cases $(63 \%)$ and in addition cytologically in 135 cases $(23 \%)$. Squamous cell carcinoma was the most common histological type $(40 \%)$, the proportion of adenocarcinoma being $26 \%$, small cell carcinoma $24 \%$ and large cell carcinoma $4 \%$. The incidence of lung cancer had decreased significantly among males (from 87 to 63 per 100,000) compared with 20 yrs earlier but had increased among females (from 4.1 to 9.5), chiefly on account of adenocarcinoma.

The findings of this prospective study show an increase in the incidence of lung adenocarcinoma among females, a histological type which is less closely related to smoking than the other cancers. This suggests that other risk factors may play an increasing role in the aetiology of lung cancer.

Eur Respir J 1999; 13: 436-440.
\end{abstract}

Depts of *Internal Medicine and **Pathology, and ${ }^{+}$Medical Faculty, University of Oulu, Oulu University Hospital, Oulu, Finland.

Correspondence: R. Mäkitaro

Dept of Internal Medicine

Oulu University Hospital

Kajaanintie 50

FIN-90220 Oulu

Finland

Fax: 35883154139

Keywords: Cancer incidence histological types

lung cancer

Received: March 191998

Accepted after revision November 71998

Supported by the Finnish Anti-Tuberculosis Association Foundation and the Cancer Society of North Finland.

National cancer registers show an increased incidence of lung cancer, especially among females, in Western populations $[1,2]$. About 1,700 new cases of lung cancer $(42$ per 100,000) are diagnosed annually among males in Finland, 64 per 100,000 in the European Community (EC) and $71-80$ per 100,000 in the USA, with the corresponding figures for females being 8.4, 8.2 and 25.8-42.9 [3-5]. Patients diagnosed with lung cancer are older than a few decades ago $[6,7]$, which may have an impact on diagnostic investigations, histology and treatment. Furthermore, the histological types of lung cancer may be changing independently [6-12]. Treatment modalities may have changed now that multimodality treatment strategies have been introduced in some centres $[13,14]$. Most previous studies on lung cancer have been conducted on hospital series or patient registers, but these give deficient information on the incidence of the disease and its treatment. This is especially true of lung cancer, since many cases may remain undiagnosed, patients are not necessarily referred and differences in the treatment policy between countries and centres cause further selection. Only a few prospective epidemiological studies are available in which the incidence and histology of lung cancer have been systematically assessed in terms of data obtained from the national cancer register [15-17].

To investigate the presentation, incidence, histology and surgical treatment of lung cancer, a prospective epidemio- logical survey was conducted. Since a similar survey had been performed $20 \mathrm{yrs}$ earlier in the same geographical district [17], the new results could be compared with those obtained at that time.

\section{Materials and methods}

The survey area was the province of Oulu in northern Finland $\left(56,000 \mathrm{~km}^{2}\right)$, with a population of 442,900 at the end of 1991. All five hospitals in the province were informed of the survey and requested to refer all suspected cases either to the Päivärinne Hospital or to the Oulu University Hospital, the latter being the only hospital performing thoracic surgery in this area. If the patient was not referred, the authors requested to be informed of the case. Most of the adult patients with an intrathoracic tumour diagnosed between January 1, 1990 and December 31, 1992 (72\%) were personally interviewed by two of the investigators. Otherwise, data were derived from the national cancer register and the patient records, and analysed retrospectively (28\%). Diagnostic investigations included fibreoptic bronchoscopy (75\%) and computed tomography (CT) (60\%). Other examinations were performed as indicated. Exsmokers were defined as people who had quit smoking at least 6 months before the diagnosis of lung cancer.

The histological specimens were processed and stained as suggested by the World Health Organization (WHO) 
[18]. All histological and cytological slides were re-examined by an experienced lung pathologist (P. Pääkkö). The lung cancers were classified into five groups according to their histological or cytological picture: 1) squamous cell carcinoma; 2) small cell carcinoma; 3) adenocarcinoma; 4) large cell carcinoma; and 5) other or unclassified forms. The last group included mainly cases where the sample was inadequate for classification but allowed the diagnosis of a malignant tumour (18 cases).

In the same geographical area 20 yrs earlier, during the years 1968-1971, a similar population-based, prospective survey of lung cancer was made by HuHTI et al. [17] using the same method of patient recognition. That survey also included all new lung cancer patients from that area during those years. All of the histological and cytological slides were similarly reviewed by experienced lung pathologists, thus making comparison of these two surveys possible.

The statistical comparison was performed using the Chisquared test and odds ratios with $95 \%$ confidence intervals (CI). A p-value $<0.05$ was considered significant. Ageadjusted incidence rates were calculated by the direct method using the world standard population as a standard [4].

\section{Results}

The number of new lung cancer cases was $602(84.7 \%$ males, $15.3 \%$ females). The annual age-standardized incidence per 100,000 was 63 for males and 9.5 for females, whereas the incidence 20 yrs ago had been 87 for males and 4.1 for females (94 and 6\%, respectively) [17]. The mean \pm SD age was $67.7 \pm 9.9$ yrs and did not differ significantly between the males $(67.7 \pm 9.8 \mathrm{yrs})$ and females (68.1 $\pm 12.7 \mathrm{yrs})$, but was higher than $20 \mathrm{yrs}$ ago (61.8 males and 62.3 females) (95\% CI for age difference 4.6-7.0). The cause for the initial examination was known in 584 cases and in most cases it had been conducted on the patient's own initiative because of symptoms. The majority of patients $(93 \%)$ had been suffering from the typical symptoms of lung cancer, such as cough, dyspnoea, haemoptysis and fatigue. In 123 cases $(21 \%)$ the cancer was found in an examination for another disease and in $22(4 \%)$ the cancer was initially suspected on the basis of a chest radiograph taken for a health examination. The cancer was diagnosed at autopsy without any previous suspicion of the disease in eight cases (1\%), the mean age of these patients being 64.1 yrs. Information from the Finnish Cancer Register revealed that three patients had not been reported $(0.5 \%)$ and four additional cases had been misclassified by the cancer registry as other types of cancer due to inadequate information.
A histological diagnosis was obtained in 381 cases (63\%). In 343 cases the tissue specimen was from the primary tumour and in 38 cases from metastases. In 20 cases a biopsy was obtained from the pleura, or cervical, mediastinal or axillary lymph nodes. In total, 79 autopsies were performed $(13 \%)$. A cytological diagnosis without histology was available in 135 cases $(23 \%)$. For 70 males $(14 \%)$ and 16 females $(17 \%)$, the diagnosis was based on clinical findings without histological or cytological confirmation (table 1). The patients without confirmation of the diagnosis were older than the others: their mean \pm SD age was $73.5 \pm 9.1 \mathrm{yrs}$ and the age difference was statistically significant $(\mathrm{p}<0.001)$.

The previous series 20 yrs earlier had comprised 446 patients, and $84 \%$ of their diagnosis had been confirmed histologically and $12 \%$ cytologically. The number of autopsies had been 138 (31\%) [17].

\section{Histological types}

The distribution of histological types is shown in tables 2 and 3 . The most common type was squamous cell carcinoma $(40 \%)$, which accounted for $43 \%$ of all cases among the males and $20 \%$ among the females. The overall proportion of adenocarcinoma was $26 \%$, with $23 \%$ among the males and $46 \%$ among the females. The percentages of small cell carcinoma among the males and females were very similar, 23 and $25 \%$, respectively. The histological distribution differed between males and females $\left(\chi^{2}=46.7,4\right.$ degrees of freedom, $p<0.001$; fig. 1). A bronchoalveolar subtype of adenocarcinoma was found in six out of the 100 male patients $(6 \%)$ with adenocarcinoma and in six out of $34(18 \%)$ female patients. Large cell carcinoma was found in $4 \%$ of cases. In addition, six adenosquamous carcinomas, one low-grade sarcoma, one carcinosarcoma, two lymphomas, two adenoid cystic carcinomas, three carcinoid tumours and 18 unclassified malignant tumours were detected. The mean age did not differ significantly between the histological types.

The percentage of adenocarcinoma among the females had increased from 27 to $46 \%$ and that among the males from 11 to $23 \%$ compared with the situation 20 yrs earlier (table 3) [17]. The annual age-adjusted incidence of adenocarcinoma per 100,000 had increased from 9 to 13 for males and from 1.2 to 3 for females.

\section{Smoking history}

The smoking habits of 558 patients were known. Eleven $(2 \%)$ of the males and $27(29 \%)$ of the females were life-long nonsmokers, while all the others were exsmokers

Table 1. - Confirmation of the diagnosis of lung cancer in the years 1968-1971 [17] and 1990-1992

\begin{tabular}{|c|c|c|c|c|c|c|}
\hline \multirow[b]{2}{*}{ Diagnosis } & \multicolumn{2}{|c|}{ Males } & \multicolumn{2}{|c|}{ Females } & \multicolumn{2}{|c|}{ Total } \\
\hline & 1968-1971 & 1990-1992 & 1968-1971 & 1990-1992 & 1968-1971 & 1990-1992 \\
\hline Histological & $350(83)$ & $319(63)$ & $26(100)$ & $62(68)$ & $376(84)$ & $381(63)$ \\
\hline Cytological & $55(13)$ & $121(23)$ & $0(0)$ & $14(15)$ & $55(12)$ & $135(23)$ \\
\hline Clinical & $15(4)$ & 70 (14) & $0(0)$ & $16(17)$ & $15(4)$ & $86(14)$ \\
\hline Total & $420(100)$ & $510(100)$ & $26(100)$ & $92(100)$ & $446(100)$ & $602(100)$ \\
\hline
\end{tabular}

Data are shown as $\mathrm{n}(\%)$. 
Table 2. - Lung cancers by histological type in 405 males in the years 1968-1971 [17] and 440 males in the years 19901992 with histological or cytological confirmation of malignancy

\begin{tabular}{|c|c|c|c|c|c|c|}
\hline \multirow[b]{2}{*}{ Carcinoma type } & \multicolumn{2}{|c|}{ Histological confirmation } & \multicolumn{2}{|c|}{ Cytological confirmation } & \multicolumn{2}{|c|}{ Total } \\
\hline & $1968-1971$ & 1990-1992 & $1968-1971$ & 1990-1992 & $1968-1971$ & 1990-1992 \\
\hline Squamous cell & $159(45)$ & 137 (43) & $32(57)$ & $52(43)$ & $191(47)$ & $189(43)$ \\
\hline Small cell & $105(30)$ & $76(24)$ & $3(5)$ & $26(22)$ & $108(27)$ & $102(23)$ \\
\hline Adenocarcinoma & 37 (11) & $67(21)$ & $6(11)$ & $33(27)$ & 43 (11) & $100(23)$ \\
\hline Large cell & $18(5)$ & $20(6)$ & $0(0)$ & $3(2)$ & $18(4)$ & $23(5)$ \\
\hline Other/unclassified & $31(9)$ & $19(6)$ & $14(25)$ & $7(6)$ & 45 (11) & $26(6)$ \\
\hline Total & $350(100)$ & 319 (100) & $55(100)$ & $121(100)$ & $405(100)$ & $440(100)$ \\
\hline
\end{tabular}

Data are shown as $\mathrm{n}(\%)$. Significant difference in histological distribution by Chi-squared test between the two series, $\mathrm{p}<0.001$.

or smokers. The percentage of adenocarcinomas was significantly higher in the nonsmokers $(50 \%)$ than in the smokers and exsmokers $(21 \%)$, with an odds ratio of $3.8(95 \%$ CI $2.0-7.4, \mathrm{p}=0.0001)$. The percentage of adenocarcinomas among nonsmokers was similar to that recorded $20 \mathrm{yrs}$ earlier (50\%) [17]. Passive smoking was not recorded for this study.

\section{Other risk factors}

None of the patients had been exposed to uranium or heavy metals. According to the Finnish Centre for Radiation and Nuclear Safety, the radon content of ambient air in this northern part of Finland is low. Occupational asbestos exposure was reported by 145 of the patients (24\%), whereas it was not recorded in the earlier series. Ten patients $(2 \%)$ in the earlier series and 22 patients $(4 \%)$ in the new series had a family history of lung cancer (parents).

\section{Treatment}

The $123(20 \%)$ patients operated on included 57 (46\%) with squamous cell carcinoma, 41 (33\%) with adenocarcinoma, $11(9 \%)$ with large cell carcinoma and five (4\%) with small cell carcinoma. Nine additional cases of operated patients included adenosquamous cell carcinomas, carcinoid tumours, adenomatoid cystic carcinoma and sarcoma. Seven additional explorative thoracotomies were performed. Resections were significantly more frequent in the younger age group (18-59 yrs) than in the older group ( $>60 \mathrm{yrs}$ ), i.e. 36 versus $17 \%$ (difference between the proportion of resection rates: 19\%, 95\% CI 9-29\%, p<0.001). The percentage of surgical treatment was very similar to that recorded 20 yrs earlier $(16 \%)$, but older ( $>60$ yrs) patients were operated on more often than previously (17 versus $6 \%$ ) [17].

\section{Discussion}

Series of lung cancer patients are usually based on cancer registers or selected hospital populations. In this prospective epidemiological study the current cancer incidence and histology were compared with the situation that prevailed 20 yrs ago and with the figures of the Finnish Cancer Register. It was found that the incidence decreased in males, but increased in females, mainly owing to an increase in adenocarcinoma.

Lung cancer is one of the most common malignancies in the world. Cancer registers show that lung cancer accounts for $21 \%$ of all cancer cases among males and $4 \%$ among females in the European Community (EC) [1]. In Finland, and in many other countries as well, prostate cancer is the most common cancer among males and breast cancer among females. Lung cancer causes $29 \%$ of all cancer deaths among males and $8 \%$ among females in the EC, with the corresponding figures gathered from "Statistics Finland" being the same, 29 and $8 \%$. According to the present results, the incidence of lung cancer in northern Finland was 31.4 per 100,000 , whereas it had been 53 per 100,000 in this area 20 yrs earlier [17].

The increase in lung cancer among females follows the trend in cigarette smoking. Likewise, the percentage of female lung cancer patients has increased from 6 to $15 \%$ in northern Finland during the last 20 yrs [17]. The present results suggest that, in particular, adenocarcinoma among females has increased during the past $20 \mathrm{yrs}$, its proportions being $27 \%$ (seven patients) and $46 \%$ (35 patients), respectively. This result is in agreement with reports from cancer registers in other countries [9, 19]. The three largest studies, published for populations in the USA by Wu et al. [19], DoDDS et al. [11] and TRAvis et al. [20], all suggest that the age-adjusted incidence of adenocarcinoma is

Table 3. - Lung cancers by histological type in 26 females in the years 1968-1971 [7] and in 76 females in the years 19901992

\begin{tabular}{|c|c|c|c|c|}
\hline \multirow[b]{2}{*}{ Carcinoma type } & \multicolumn{2}{|c|}{ Histological confirmation } & \multirow{2}{*}{$\frac{\text { Cytological confirmation }}{1990-1992}$} & \multirow{2}{*}{$\frac{\text { Total }}{1990-1992}$} \\
\hline & 1968-1971 & 1990-1992 & & \\
\hline Squamous cell & $7(27)$ & $11(17)$ & $4(29)$ & $15(20)$ \\
\hline Small cell & $7(27)$ & $15(24)$ & $4(29)$ & $19(25)$ \\
\hline Adenocarcinoma & $7(27)$ & $30(48)$ & $5(35)$ & $35(46)$ \\
\hline Large cell & $3(12)$ & $0(0)$ & $0(0)$ & $0(0)$ \\
\hline Other/unclassified & $2(8)$ & $6(10)$ & $1(7)$ & 7 (9) \\
\hline Total & $26(100)$ & $62(100)$ & $14(100)$ & $76(100)$ \\
\hline
\end{tabular}

All cases in the older series were confirmed histologically and those in the newer series either histologically or cytologically. Data are shown as n (\%). Significant difference in histological distribution by the Chi-squared tests between the two series, $\mathrm{p}=0.026$. 

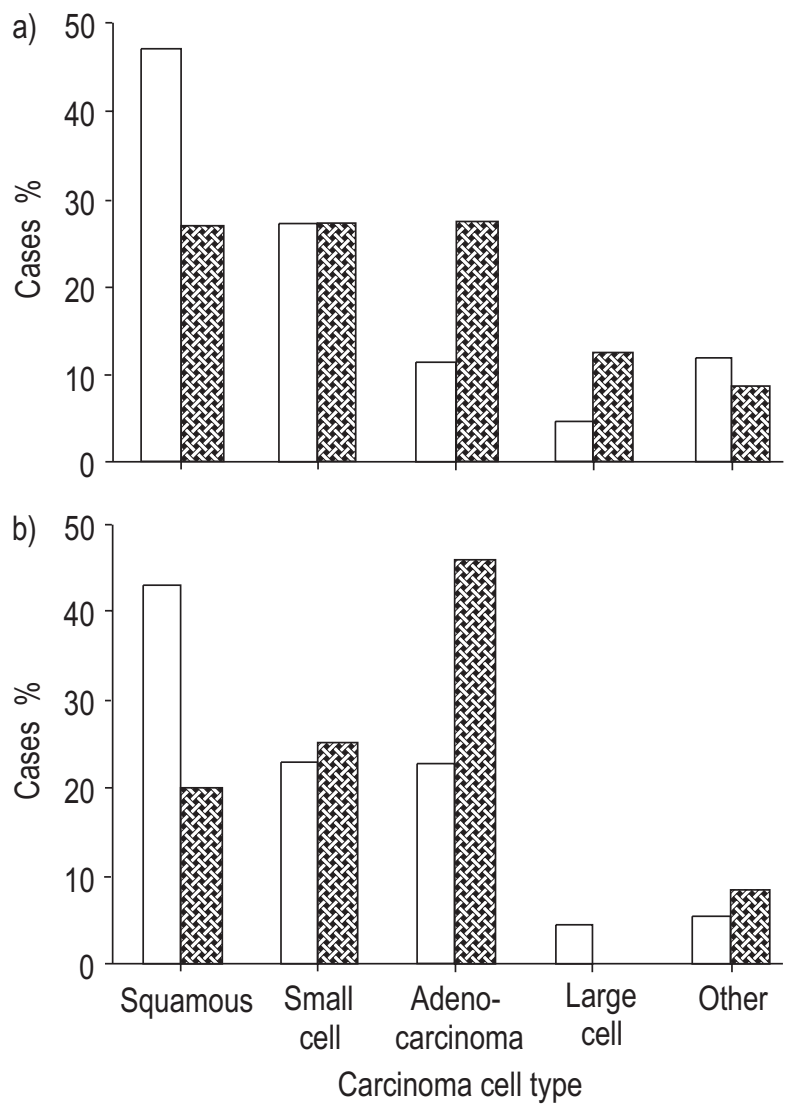

Fig. 1. - Percentages of males $(\square)$ and females (获) with each carcinoma cell type in the years 1968-1971 (a) and 1990-1992 (b).

increasing. All of these studies were retrospective and register-based without any pathological review of slides. Only one longitudinal study has been conducted in Europe, in the Netherlands, and this similarly showed an increase in the incidence of adenocarcinoma [21]. However, some surveys have failed to show this change: a study from the Tumor Register of New Mexico showed an increasing proportion of small cell carcinoma among the female population rather than adenocarcinoma, but again histological diagnosis was available in only half of the cases [22]. A retrospective, population-based study from Minnesota, USA, showed an equal increase in all histological cell types of bronchogenic carcinoma; here, $96 \%$ of the cases had histological confirmation and all the slides had been re-evaluated [8]. A trend towards an increase in adenocarcinoma among females and nonsmokers has also been reported by DodDs et al. [11], Ko et al. [23] and HiraYAMA [24].

The frequency of autopsies is lower now than $20 \mathrm{yrs}$ ago (13 versus $31 \%$ ), which is partly associated with altered legislation in Finland. If histological or cytological diagnosis was not available, only radiologically typical cases of lung cancer were included in this study. In these cases other diseases had been excluded by bronchofibrescopy and CT in most cases.

Given that adenocarcinomas are less closely related to smoking, the increase of adenocarcinoma suggests additional risk factors that may play an important role in the aetiology of lung cancer. Passive smoking was not re- corded in this series of patients. Most of the patients started with nonfiltered cigarettes but smoked filtered cigarettes most of their smoking time. The use of filtered cigarettes was more common in the new material than in the older one and this change has been suggested to contribute to the increase in adenocarcinomas [10]. Advanced needle biopsy technique and flexible bronchofibreoscopy have facilitated access to the lung periphery, which may also increase the proportion of more peripheral tumours, such as adenocarcinoma. It is theoretically possible that some of the adenocarcinomas of this study represent gynaecological primary tumours. However, these tumours are diagnosed more accurately now than earlier since both mammography and CT are widely available. The study was conducted in northern Finland, where the environmental factors have not changed over the years. No pollution or exposure to radon or uranium was detectable. Occupational asbestos exposure was documented in $24 \%$ of males. However, it is not likely that asbestos influenced the increase of adenocarcinoma among females in this study.

The WHO standards for histological processing are designed for surgical and autopsy samples, for which they are suitable and work well. Smaller samples, such as those taken by bronchofibreoscopy, are more problematic in the WHO classification, but squamous cell, adenomatoid and small cell differentiation are still recognizable. Large cell differentiation is difficult to identify in small biopsy samples and this may be a potential source of error. In this survey cytological samples were used together with small biopsies to decide on a histological type and this was especially helpful in squamous and small cell differentiation. Since the latest WHO standard does not include the diagnosis of undifferentiated carcinoma, this term was used only in cases where the bronchoscopy sample was inadequate for classification but allowed the diagnosis of a malignant tumour.

Lung cancer is often beyond curative treatment. Since recent studies have shown a better prognosis among patients with stage IIIa disease [14, 25], one might expect that the number of resected cases is increasing. However, only a minority of all new lung cancers are operated on, $\sim 10 \%$ in Scotland [26], $20 \%$ in the Netherlands [27], 25\% in Spain [28] and 10\% in the USA [29]. These figures are derived from selected patient series, usually collected from hospitals and, hence, they still overestimate the number of patients treated surgically. In the present survey, $20 \%$ of the new cases in northern Finland were operated on between 1990 and 1992, compared with 16\% 20 yrs earlier [17]. These series comprised all known patients, including those with low performance status who were treated in primary centres without hosptial admission. It should also be noted that the present series was collected before the possible benefits of combined treatment modalities had been made public. No major changes in the surgical treatment of lung cancer are likely to have taken place during the past few years. The reason for the unchanged frequency of surgery over the past 20 yrs may be associated with the continuing difficulty in diagnosing limited disease, the relative increase in lung cancer among old people and/or the unchanged attitude towards the treatment of these patients. The proportion of older patients ( $>60 \mathrm{yrs}$ ) operated on had increased from 6 to $17 \%$ during the last 20 yrs and it is accepted that the operative risk for elderly patients is not markedly higher than that for younger patients [30]. 
Based on this prospective population-based study, it can be concluded that lung adenocarcinoma in particular is increasing among females in northern Finland. The frequency of surgical operations has not changed over the last 20 yrs, with $20 \%$ of all new cases of lung cancer being treated surgically.

\footnotetext{
Acknowledgements. The co-operation of L. Teppo from the Finnish Cancer Registry is gratefully appreciated.
}

\section{References}

1. Jensen OM, Esteve J, Moller H, Renard H. Cancer in the European Community and its member states. Eur J Cancer 1990; 26: 1167-1256.

2. Devesa SS, Silverman DT, Young JL Jr, et al. Cancer incidence and mortality trends among whites in the United States, 1947-84. J Natl Cancer Inst 1987; 79: 701-770.

3. Finnish Cancer Registry. Cancer incidence in Finland 1995. Helsinki, Cancer Society of Finland Publication No. 56, 1997.

4. Parkin DM, Muir CS, Whelan SL, Gao YT, Ferlay J, Powell J. Cancer incidence in five continents. IARC Scientific Publication No. 120. Vol. VI Lyon, International Agency for Research on Cancer, 1992.

5. Zheng T, Holdorf TR, Boyle P, et al. Time trend and the age-period-cohort effect on the incidence of histologic types of lung cancer in Connecticut, 1960-1989. Cancer 1994; 74: 1556-1567.

6. Coggon D, Acheson ED. Trends in lung cancer mortality. Thorax 1983; 38: 721-723.

7. Connolly CK, Jones WG, Thorogood J, Head C, Muers MF. Investigation, treatment and prognosis of bronchial carcinoma in the Yorkshire region of England 19761983. Br J Cancer 1990; 61: 579-583.

8. Beard CM, Jedd MB, Woolner LB, Richardson RL, Bergstralh EJ, Melton LJ. Fifty-year trend in incidence rates of bronchogenic carcinoma by cell type in Olmsted County, Minnesota. J Natl Cancer Inst 1988; 80: 1404-1407.

9. Rennert G, Rennert HS, Epstein L. Lung cancer histology in Jews and Arabs in Israel, 1962-1982. Am Rev Respir Dis 1991; 143: 721-726.

10. Charloux A, Quoix E, Wolkove N, Small D, Pauli G, Kreisman $\mathrm{H}$. The increasing incidence of lung adenocarcinoma: reality or artefact? A review of the epidemiology of lung adenocarcinoma. Int J Epidemiol 1997; 26: 14-23.

11. Dodds L, Davis S, Polissar L. A population-based study of lung cancer incidence trends by histological type, 1974-1981. J Natl Cancer Inst 1986; 6: 21-29.

12. el-Torky M, el-Zeky F, Hall JC. Significant changes in the distribution of histologic types of lung cancer. A review of 4928 cases. Cancer 1990; 65: 2361-2367.
13. Rosell R, Gomez-Codina J, Camps C, et al. A randomised trial comparing preoperative chemotherapy plus surgery with surgery alone in patients with non-small-cell lung cancer. N Engl J Med 1994; 330: 153-158.

14. Mountain CF. Expanded possibilities for surgical treatment of lung cancer. Survival in stage IIIa disease. Chest 1990; 97: 1045-1051.

15. Nou E, Stenkvist B, Graffman S. Bronchial carcinoma I. A prospective five year study of an unselected carcinoma population in a Swedish County. Scand J Respir Dis 1979; Suppl. 104: 43-82.

16. Edinburgh Lung Cancer Group. Patients presenting with lung cancer in South East Scotland. Thorax 1987; 42: 853-857.

17. Huhti E, Sutinen S, Reinilä A, Poukkula A, Saloheimo M. Lung cancer in a defined geographical area: history and histological types. Thorax 1980; 35: 660-667.

18. World Health Organization. Histological typing of lung tumours. International Classification of Tumors, No. 1, 2nd Edn. Geneva, World Health Organization, 1981.

19. Wu AH, Henderson BE, Thomas DC, Mack TM. Secular trends in histologic types of lung cancer. J Natl Cancer Inst 1986; 7: 53-56.

20. Travis WD, Travis LB, Devesa SS. Lung cancer. Cancer 1995; Suppl. 75: 191-202.

21. Janssen-Heijnen ML, Nab HW, van Reek J, van der Heijden LH, Schipper R, Coebergh JW. Striking changes in smoking behaviour and lung cancer incidence by histological type in south-east Netherlands, 1960-91. Eur J Cancer 1995; 31A: 949-952.

22. Butler C, Samet JM, Humble CG, Sweeney ES. Histopathology of lung cancer in New Mexico, 1970-72 and 1980-81. J Natl Cancer Inst 1987; 8: 85-90.

23. Ko $\mathrm{YC}$, Lee $\mathrm{CH}$, Chen $\mathrm{MJ}$, et al. Risk factors for primary lung cancer among non-smoking women in Taiwan. Int $J$ Epidemiol 1997; 26: 24-31.

24. Hirayama T. Non-smoking wives of heavy smokers have a higher risk of lung cancer: a study of Japan. Br Med $J$ (Clin Res Edn) 1981; 282: 183-185.

25. Roth JA, Fossella F, Komaki R, et al. A randomized trial comparing preoperative chemotherapy and surgery with surgery alone in resectable stage IIIA non-small-cell lung cancer. J Natl Cancer Inst 1994; 86: 673-680.

26. Fergusson RJ, Gregor A, Dodds R, Kerr G. Management of lung cancer in South East Scotland. Thorax 1996; 51: 569-574.

27. Damhuis RA, Schutte PR. Resection rates and postoperative mortality in 7899 patients with lung cancer. Eur Respir J 1996; 9: 7-10.

28. Mane JM, Estape J, Sanchez-Lloret J, et al. Age and clinical characteristics of 1433 patients with lung cancer. Age Ageing 1994; 23: 28-31.

29. Zagonel V, Pinto A, Serraino D, et al. Lung cancer in the elderly. Cancer Treat Rev 1994; 20: 315-329.

30. Roxburgh JC, Thompson J, Goldstraw P. Hospital mortality and long-term survival after pulmonary resection in the elderly. Ann Thorac Surg 1991; 51: 800-803. 